\title{
The Effects of Framing on Inter-group Negotiation
}

\author{
Petru Lucian Curşeu • Sandra Schruijer
}

Published online: 19 October 2007

(C) Springer Science+Business Media B.V. 2007

\begin{abstract}
The present paper explores the way in which groups cognitively represent information framed as danger and the way in which such collective cognitive representations influence group performance during inter-group negotiations. One hundred and two participants were distributed over 34 three-person groups and were involved in a negotiation game developed by Lewicki et al. (1999, Negotiation: readings, exercises and cases. McGraw-Hill, Boston). The groups were organized in 17 pairs and each pair played the negotiation game in two rounds. The game rules and the available resources were the same for both groups, but one of the groups in each pair received the game information framed as "danger", while the other group in the pair received a neutral framing. The groups with a "danger" frame developed a more defensive strategy during negotiations, adopted more often a collaborative approach and had a significantly lower performance as compared to the groups in the non-framing condition.
\end{abstract}

Keywords Inter-group negotiation · Framing $\cdot$ Cognitive representations

The framing of information as danger has a strong and pervasive effect on human behavior because perceived threats induce fear and negative emotions (Jarymowicz and Bar-Tal 2006), and because the human cognitive system is very sensitive to negatively framed information (Fiske and Taylor 1991; Ito et al. 1998; Ito and Cacioppo 2005), especially to information signaling danger (Curşeu 2003; Miclea and Curşeu 2003). Such a sensitivity serves an evolutionary function (Baumeister et al. 2001; Miclea and Curşeu 2003). At the individual level of analysis, the effects of this sensitivity have been extensively studied in a variety of tasks from decision-making (Ito et al. 1998) to social judgments (Yzerbyt and Leyens 1991; Lupfer et al. 2000; Ito and Cacioppo 2005). However, the effects of negatively framed information

P. L. Curşeu (凶)

Department of Organisation Studies, Tilburg University, Room P1.161, Warandelaan 2, P.O. Box 90153,

Tilburg, NL 5000LE, The Netherlands

e-mail: P.L.Curseu@uvt.nl

S. Schruijer

Utrecht School of Governance, University of Utrecht, Utrecht, The Netherlands 
(e.g. information framed as danger) on information processing in groups received little or no attention in the literature. In this paper we will empirically explore the effects of framing in terms of danger on group decision making in inter-group negotiation situations.

The impact of framing on individual decisions has been extensively studied in the literature. Some scholars (Levin et al. 1998) rightfully argue that "the framing effect" is one of the most prolific areas in individual decision-making research. The framing effect stands for the phenomenon that small phrasing changes of decisional alternatives, with similar expected outcomes, induce a specific preference for one of the alternatives (Levin et al. 1998; Kühberger 1998; Tversky and Kahneman 1981). One key construct in the explanation of the framing effect is that of cognitive or mental representation.

Gingerenzer et al. (1991) consider the framing effect to result from the construction of a mental model of the decisional situation. This model is built around knowledge describing the decisional situation and the cognitive representations that are activated from the longterm memory (LTM). According to this model, a decision results from a comparison between the data describing the current situation and preexisting cognitive representations. A similar model suggests that the framing effect occurs because the alternatives are embedded in a cognitive causal schema (Jou et al. 1996; Olekalns and Smith 2005). In this approach, the manner in which the alternatives are presented activates congruent schemata from the LTM, schemata that lead to a selective processing of the available information and finally to a decision-making bias. Therefore, the causal schema provides the decision-maker with a referent about alternatives and about the consequences of the alternatives, which will ultimately influence the outcome of the decision-making process (Rohrbaugh and Shanteau 1999) or the outcome of the negotiation (Olekalns 1994, 1997; Olekalns and Smith 2005). Both explanatory models are similar in that they consider the role of cognitive representations in determining the decisional output.

A particular situation in which the framing effect is important is the situation in which the information is framed in negative terms inducing a so-called negativity bias (Fiske and Taylor 1991; Ito et al. 1998; Ito and Cacioppo 2005). The negativity bias refers to the higher sensitivity of the human cognitive system to negatively framed information. In the process of impression formation, expectancy disconfirming negative information overrules the effect of disconfirming positive information (Lupfer et al. 2000). For example, information that signals danger or threats outweighs the information that signals hope (Jarymowicz and Bar-Tal 2006). Miclea and Curşeu (2003) showed that individuals are more willing to allocate own as well as external resources to address a situation which is framed as danger and is perceived as a threat as compared to a situation framed as an opportunity or a problem solving situation. Therefore, the human cognitive system seems more prepared to mobilize resources in order to process negatively framed information.

Group decision-making is also affected by information framed as danger. Groups are more willing to allocate external resources, and to get personally involved in solving an issue framed as danger as compared to dealing with an issue framed as a problem or an opportunity (Curşeu 2003). The classical framing effect has been replicated in group studies too (Paese et al. 1993), the explanation being that groups tend to overuse the shared information; group discussions consist primarily of information that is held by all group members (Stasser and Titus 1985, 1987) and shared individual preferences are accentuated in group settings (Lamm 1988). The information sampling model (Stasser and Titus1985, 1987) and the group polarization model (Lamm 1988) suggest that an individual tendency of processing information in a particular way will most probably be accentuated in group settings. In other words, the use of a general decision making causal schema held by the individual group members will be accentuated in group settings. It is therefore expected that the negativity bias will hold at 
the group level too. The group as a socio-cognitive system is expected to be more sensitive to information framed as danger and to develop defensive strategies to deal with the perceived threat.

The concept of collective cognitive representation (Curşeu 2003, 2006; Hinsz et al. 1997) is essential in explaining the framing effect and the negativity bias at the group level. Within a group, each member behaves according to the representations (schemata) he/she has about the other group members, about the group's task and the context of the group. The behavior of each group member is a social stimulus for the other group members. This stimulus affects the individual representations. When representations change, individual behavior also changes. Thus the process of structuring the collective representations is a dynamic process. We consider the moment that group members reach consensus to be the point when the representation becomes stable. At that moment, the group will most probably make a decision or identify a solution to a problem in line with this representation (Curşeu 2006). Groups store these representations and use them to make decisions in similar situations. Using previously developed representations about a situation reduces the time to reach consensus and make a decision, but at the same time imposes constraints on the extent to which groups analyze the available information.

When two groups negotiate, they exchange information that will be further on used to make decisions within groups and develop strategies for further negotiations (Eden and Ackerman 2001; Olekalns 2002). When one of the groups provides relevant information, the members of the other party will use existing schemata to make sense of this information (Gingerenzer et al. 1991; Olekalns and Smith 2005). During group discussions, the group as a whole will develop a collective cognitive representation about the situation. Cognitive schemata that are congruent with this situation are activated, leading to a selective processing of the available information. Schema-congruent information is analyzed in detail, while schema-incongruent information is ignored and sometimes, when schema-congruent information does not exists it is produced (Fiske and Taylor 1991). Due to this selective information processing the performance of groups may be impaired.

When information is framed in negative terms, information processing is preferred that is consistent with this frame. It is therefore expected that during inter-group negotiations, groups that receive the negotiation information framed as danger will develop more defensive strategies as compared to groups not having received a danger frame. This is because the former group members focus more on processing the information consistent with the danger frame and the perceived threat. Focusing exclusively on the information that signals dangers will most probably reduce the amount of relevant information processed and the number of alternative strategies used in the negotiation. Therefore the hypothesis of this study is:

In inter-group negotiations groups that receive information framed as danger will adopt a more defensive strategy and will have a lower performance in the negotiation than the groups that receive the information framed in neutral terms.

We designed an experimental task in which two groups receive the same body of knowledge yet framed differently. The groups were asked to interact in a negotiation exercise, after carefully considering the available information. Our prediction was that the collective representation developed by the two groups would differ and therefore the outcomes of the negotiation game would be different. The hypothesis reflects the effects of framing on the negotiation outcomes for the group that receives a danger framed information. Because in each negotiation there are two groups involved (negotiation as a social interaction process Olekalns 2002), we study the behavior of the other party involved in the negotiation in an 
exploratory way. Research on individual negotiations showed that the behavior of one party influences the behavior of the other party involved in the negotiation (see for details the meta-analysis of Druckman 1994). Therefore, one of the questions to be answered by the present study is: does the defensive behavior of the framed group generate a more offensive strategy and behavior of the other group?

\section{Method}

\subsection{Participants}

The participants, 102 undergraduates (86 women) studying psychology at a Romanian University ("Babeş-Bolyai" University Cluj-Napoca), were distributed over 34 groups. They were told they would participate in a negotiation exercise. We videotaped the meetings. Two groups in two negotiation sessions did not agree to be filmed. In this case we made extensive notes of their strategy and their negotiation behavior.

\subsection{Procedure}

The 34 groups were organized in 17 pairs. A negotiation pair consisted of two groups of three members. At the beginning of the experimental session, some general information about the negotiation game was given to both groups from each pair. They were told that they would participate in a negotiation game and each of them received the rules of the game on an A4 format paper. The respondents were instructed to read the rules carefully and to develop a group strategy how to approach the situation. There was no time constraint for developing their strategy. The length of the strategy development process was between 1 and $2 \frac{1}{2} \mathrm{~h}$. The next step was the real negotiation.

The game is an adapted version of the "disarmament excercise" developed by Lewicki et al. (1999). One of the groups in a pair received the game information framed as danger, while the other group received the information with a neutral frame. Basically, the decision space was similar to both groups. The difference consisted only in the fact that half of the groups received the information that they are a small country that only recently gained its independence and that they are put into the situation to confront another group that represents a big and powerful country. Apart from this, all teams received the same information. It was explicitly stated that all groups have the same number of weapons, have the same rules and the same rights during negotiations. It is important to mention here that although the framing was done in terms of power (the term power was used in the game text), this is not a power manipulation because in terms of absolute power (Wolfe and McGinn 2005), both groups had the same resources and the same alternatives. It was furthermore clearly stated that the small country was independent.

The negotiation game was organized in two rounds. Each round consisted of seven steps of 3 min length, during which the groups had to make decisions about the activation of their "weapons". There was a 30-s break between the steps, during which the groups could call for negotiation or could declare an attack. Throughout the game, the groups recorded their decisions at the end of each step. The experimenter played a mediating role during the negotiations.

Each group could gain a certain number of points based on its own decision and the other group's decision. For each group, the maximum gain could be obtained when the group had a higher number of activated weapons compared to the other group and declared attack. The 
most certain gain could be obtained if no group declared attack and if at the end of the seven steps they had no weapons activated. Therefore, a normative analysis of the game proves that disarmament and collaboration (deactivating as many weapons as possible) is the optimal strategy for both parties since in this case, every party keeps its own initial number of points and adds to that a certain number of points gained from a third party, in this case the World Bank.

After the seven steps, the groups received feedback from the experimenter regarding their gained points. Then they had the opportunity to revise their strategy for the next sequence of the game, and they spent 30-60 min to reconsider their position. After that, the negotiation game repeated itself under the same specified rules.

The mediator was informed about the strategy the groups were going to use. The group decision-making was realized under time constraints. Each group had 3 min to decide about the activation of their weapons during each step of the game. The detailed description of the decision situation is presented in Appendix 1.

In sum, the independent variable of this study was the type of information received by the groups (danger framing versus no-framing) and the dependent variable were: the number of points gained by each team, the number of attacks declared on the other group, and the numbers of requested negotiations. In operational terms and related to the framing of the hypothesis, a smaller number of attacks declared and a larger number of negotiations requested are indicative for a defensive attitude, while the number of points gained is indicative for group performance in the negotiation game. In order to check the content of the group representations, the themes that emerged during the negotiations are also used in the analyses. A quantitative coding strategy described by Weingart et al. (2004) was used for the themes that emerged during negotiation. The results of these analyses were mostly used for the exploratory part of our study. The first author made a preliminary analysis of the themes that emerged in negotiations, these themes were listed, and then both authors discussed and clustered them based on their content similarity in 15 general themes (for a list see Table 2). The frequencies of these final themes were then recorded for each game round.

\section{Results}

The summary of the results is presented in Table 1. Groups that received no framing gained a significantly higher number of points than the other groups (Mann-Whitney test, $Z=2.605$, $P<0.009$ ). The groups in the framing condition declared only three attacks in each of the game rounds while the groups which received no framing declared 11 and 12 attacks, respectively.

Groups that received the danger-framed information developed a more defensive strategy compared to the no-framing condition. This conclusion is also supported by the analysis of

Table 1 The results for the two rounds of the negotiation game

\begin{tabular}{llclrc}
\hline Round & Group & $\begin{array}{l}\text { Average points } \\
\text { gained }\end{array}$ & $\begin{array}{l}\text { Average activated } \\
\text { weapons }\end{array}$ & $\begin{array}{l}\text { No. of } \\
\text { attacks }\end{array}$ & $\begin{array}{l}\text { No. of negotiations } \\
\text { requested }\end{array}$ \\
\hline Round 1 & Danger- framing & 5.92 & 12.76 & 3 & 18 \\
& No-framing & 10.54 & 14.58 & 11 & 2 \\
\multirow{2}{*}{ Round 2 } & Danger- framing & 5.68 & 13.41 & 3 & 6 \\
& No-framing & 11.42 & 12.88 & 12 & 3 \\
\hline
\end{tabular}


the declared strategies. From the 17 groups in the framing condition, ten mentioned the frame in their strategy (e.g. "we are a small country, so we have to persuade them to collaborate in order to keep our independence") and nine of these groups opened at least one negotiation session with this argument. Opening a negotiation session by explicitly stating the inferiority of one's party leads to an unfavorable position throughout the whole negotiation. This is a clear indicator of the fact that the groups involved in negotiations developed different cognitive representations about the decision space. Thus, even if the decision space was similar, the group decisions and their negotiation behavior differed according to the cognitive representation the group has formed. This collective representation was slightly modified after the first round of the game. From the groups that received the framing, only five have modified their strategy for the second round. From the groups that received no framing, ten modified their strategy for the second round. At the end of the second round, the difference between the two experimental conditions was enlarged (see Table 1).

In order to have a more thorough perspective on the differences in the collective cognitive representations between the danger-framed and neutral-framed groups we analyzed the videotaped material, identifying the main topics brought up during the negotiations and their absolute frequency. Since the groups were paired and the length of the negotiation was basically the same for the two groups in a pair, we controlled for the time length of the negotiations. Fourteen main topics (plus the small country argument, which is only relevant for the groups in the framing condition) recurrently occurred during the negotiations. The means, standard deviations and correlations among the negotiations themes and the other variables considered in the study are presented in Table 2.

Eight topics significantly differentiated between danger-framed and neutral-framed groups. The mean ranks and the results of the Mann-Whitney test for the comparison between the danger framed and neutral-framed groups are presented in Table 3.

The first topic refers to asking the other party to collaborate and not to compete or declare attacks on each other. This collaborative strategy was brought up more often by the danger-framed groups (Mann-Whitney test, $\mathrm{Z}=2.45, P<0.01$ ). However, groups that received no framing refused collaboration much more often than the groups that received the danger framing (Mann-Whitney test, $\mathrm{Z}=2.53, P<0.01$ ). Furthermore the danger-framed groups expressed more often the intention to collaborate (Mann-Whitney test, $\mathrm{Z}=3.27, P<0.001$ ) and pacifist intentions (Mann-Whitney test, $\mathrm{Z}=3.49, P<0.0001$ ) than groups in the noframing condition. These issues are also highly and positively correlated (see Table 2) suggesting the pursuit of a general collaborative strategy especially followed by the groups that received the danger-framed game information. Also the number of requested negotiations is significantly and positively correlated to the above mentioned topics. That means that groups that asked for negotiations did so in order to ask information about the other party and to set the stage for collaboration.

Another relevant topic that came to light during the negotiations, illustrating the defensive attitude of the groups that received the danger framing, refers to the questions about the other group's intentions (e.g. "What do you really want from us?", "What do you want us to do?", "What do you know about us?"). Such questions were asked more often by the danger-framed groups (Mann-Whitney test, $\mathrm{Z}=2.66, P<0.008$ ). The frequency of this topic is also positively correlated with the collaboration related topics and with the number of negotiations requested by the groups. The use of this topic during negotiations is illustrative for the self-depreciating strategy used by the groups that received the game information framed as danger. In conclusion, the hypothesis of this study stating that the groups that receive the game information framed as danger will adopt a more defensive strategy than the groups that 


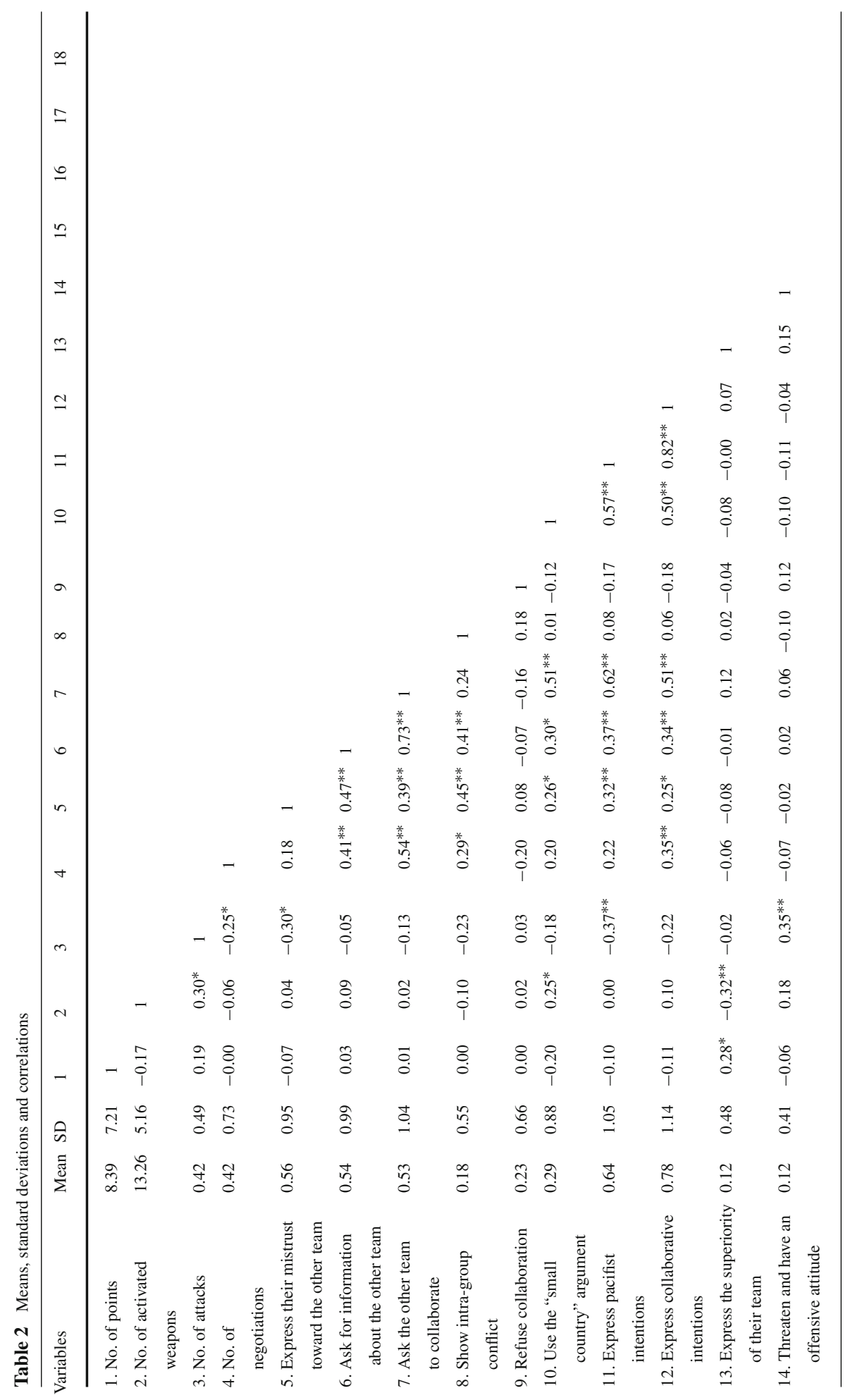




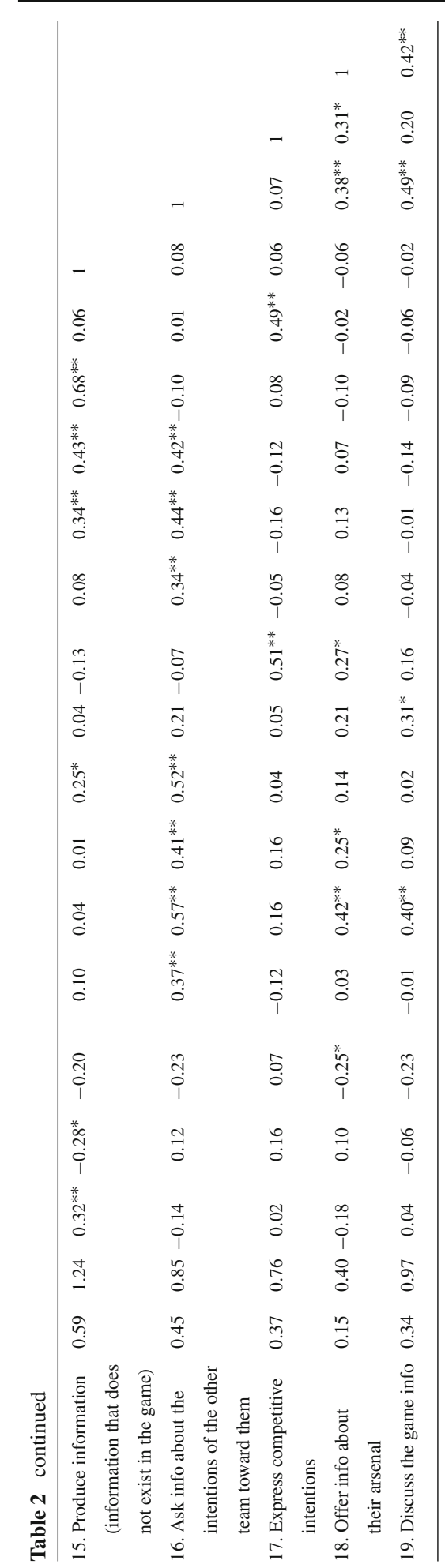

\section{照 Springer}


Table 3 The mean ranks and the results of Mann-Whitney test for the comparison of the topics used during negotiations by the danger-framed (framing) and neutral framed groups (no-framing)

\begin{tabular}{|c|c|c|c|}
\hline Negotiation themes & Group & Mean rank & Z (sig.) \\
\hline \multirow[t]{2}{*}{ Express their mistrust toward the other team } & Framing & 35.20 & $-1.41(0.15)$ \\
\hline & No-framing & 29.80 & \\
\hline \multirow[t]{2}{*}{ Ask for information about the other team } & Framing & 33.69 & $-0.61(0.53)$ \\
\hline & No-framing & 31.31 & \\
\hline \multirow[t]{2}{*}{ Ask the other team to collaborate } & Framing & 37.91 & $-2.45(0.01)$ \\
\hline & No-framing & 27.91 & \\
\hline \multirow[t]{2}{*}{ Show intra-group conflict } & Framing & 33.52 & $-0.77(0.44)$ \\
\hline & No-framing & 31.47 & \\
\hline \multirow[t]{2}{*}{ Refuse collaboration } & Framing & 28.94 & $-2.53(0.01)$ \\
\hline & No-framing & 36.06 & \\
\hline \multirow[t]{2}{*}{ Express pacifist intentions } & Framing & 39.36 & $-3.49(0.0001)$ \\
\hline & No-framing & 25.64 & \\
\hline \multirow[t]{2}{*}{ Express collaborative intentions } & Framing & 39.19 & $-3.27(0.001)$ \\
\hline & No-framing & 25.81 & \\
\hline \multirow[t]{2}{*}{ Express the superiority of their team } & Framing & 30.00 & $-2.30(0.02)$ \\
\hline & No-framing & 35.00 & \\
\hline \multirow[t]{2}{*}{ Threaten and have an offensive attitude } & Framing & 29.50 & $-2.55(0.01)$ \\
\hline & No-framing & 35.50 & \\
\hline \multirow[t]{2}{*}{ Produce information (information that does not exist in the game) } & Framing & 30.89 & $-0.86(0.39)$ \\
\hline & No-framing & 34.11 & \\
\hline \multirow[t]{2}{*}{ Ask info about the intentions of the other team toward them } & Framing & 37.20 & $-2.60(0.009)$ \\
\hline & No-framing & 27.80 & \\
\hline \multirow[t]{2}{*}{ Express competitive intentions } & Framing & 27.27 & $-2.97(0.003)$ \\
\hline & No-framing & 37.73 & \\
\hline \multirow[t]{2}{*}{ Offer info about their arsenal } & Framing & 32.92 & $-0.30(0.76)$ \\
\hline & No-framing & 32.08 & \\
\hline \multirow[t]{2}{*}{ Discuss the game info } & Framing & 31.55 & $-0.60(0.54)$ \\
\hline & No-framing & 33.45 & \\
\hline
\end{tabular}

received no framing was fully supported by the data. The data also show a positive association between the defensive strategy and the collaborative topics used during negotiations.

A second aim of the study was to check if the groups in the no-framing condition are influenced by the strategy used by the framed groups. Our results show that the groups in the no-framing condition adopted a more competitive and offensive strategy. These groups expressed competitive intentions (Mann-Whitney test, $\mathrm{Z}=2.97, P<0.003$ ), threaten and had an offensive attitude during negotiations (Mann-Whitney test, $\mathrm{Z}=2.55, P<0.01$ ) more often than the danger-framed groups. The neutral-framed groups also openly expressed the superiority of their party during negotiations more often than the danger framed groups did (Mann-Whitney test, $\mathrm{Z}=2.30, P<0.02$ ). Therefore it can be concluded that the collaboration seeking and self-depreciating negotiation strategy used by the groups in the dangerframing condition was associated with a more offensive and competitive strategy used by the other party (groups in the neutral-framing condition). 


\section{Discussion}

Each group forms a collective representation about the decision space according to the way the decision situation is framed. Once a first generic representation about the decision situation is formed, the information processing is further influenced by this representation. The groups that received the game information framed as danger represent their own party as being threatened and they develop more defensive and collaborative strategies. Based on this representation, they ignore the information that made the equality between groups obvious (the equal number of weapons, the same rules, the same rights and the same initial number of points). They only focus on the information that is congruent with their representation and therefore they have a lower performance in the negotiation game. The groups that received no framing, but during negotiations are exposed to the information that the other group may feel inferior, adopt a more competitive and offensive strategy during negotiations. This also induced a selective information processing leading these groups to refuse collaboration, a strategy which would have brought them more points at the expense of an external party. They also used a more competitive strategy, which brought them more points but at the expense of the other group.

This selectivity in information processing was enhanced by the fact that the groups had to decide under time pressure (see also Stuhlmacher and Champagne 2000). Illustrative in this sense is the fact that declaring attack in the first round and gaining a higher number of points was interpreted as a sign of superiority. This competitive strategy adopted by the groups in the neutral framing condition could have been interpreted as threatening by the groups in the danger-framing condition. This interpretation is congruent with the danger framing and probably influenced their behavior during negotiations. Even if no real explicit threats were made, the groups in the framing condition may have interpreted them as threats. They could be conceptualized as implicit threats (threats in which the actions done by the perpetrator if the target does not comply are not clearly stated) (Sinaceur and Neale 2005). Since the competitive attitude (implicit threats) occurred from the very beginning of the negotiation game, it may have elicited concessions from the danger-framed groups, which are important elements emphasizing their defensive attitude.

For the groups that received the game information framed as danger, the change in the collective representation in the second phase of the game was minor. The number of attacks declared by the danger-framed groups did not significantly increase in the second round. In the second round the danger-framed groups decided rather to increase the number of activated weapons (see Table 1) in order to be prepared for an attack and did not significantly change their strategy toward a more offensive position. The relative decrease of the activated weapons in the no-framing condition could be explained as an indication that these groups analyzed the game information in a more accurate fashion after the first round and realized that both groups can gain points from a third party. The framed groups used the danger frame in the second round too, meaning that the collective representation formed during the first round was used indiscriminately in the second one. The fact that the representation formed in the danger-groups was more enduring is probably due to the negativity bias and led to using a defensive strategy further on in the game. However, the framed groups activated weapons, but did not declare attacks to the other party. This is a purely defensive act, because the other group was unaware of the status of the others' arsenal. This also explains why the difference in points between the framing and no-framing groups increased in the second round.

The mobilization of resources in the second round as a defensive strategy is consistent with previous research, which showed a tendency to allocate a higher amount of resources in order to deal with issues framed as danger as compared to issues framed as problems 
(Miclea and Curşeu 2003; Curşeu 2003). In the first round, the danger-framed groups negotiated with the other party and persuaded them not to attack. The number of negotiations requested decreased from 18 in the first round to six in the second round while the number of negotiations requested by the groups with no framing remained approximately the same. This is indicative for the more defensive attitude of the framed groups in the second round as compared with the groups in the no-framing condition.

The group decisions and the subsequent negotiation behaviors are congruent with the way in which groups represent the task and the game information. The framing as danger has a strong and persistent effect on group decision-making and group performance in negotiation situations. This is the result of two mechanisms. The first one refers to the impact of an activated representation on behavior and the second one refers to the privileged processing of information signaling danger.

The effect of an activated cognitive representation on negotiation behavior was illustrated in experimental settings (Pinkley 1990; Larrick and Blount 1997; Olekalns and Smith 2005) as well as in more ecological contexts (Gray 2004). In the field of intractable conflicts in an environmental domain the framing process was defined as the active process of constructing interpretative frames about aspects of the reality (Elliot et al. 2002). The disputants were shown to use specific cognitive frames to interpret the events, but also to promote a strategic advantage. For example framing someone as an environmentalist helps to make sense of his/her motives, interests and actions, but can also block further interaction and collaboration based on this schema or frame congruent information (Elliot et al. 2002; Hanke et al. 2002; Gray 2004). In our design, if one group represents itself as being threatened by another, they will adopt a more defensive strategy during negotiations and they will be more inclined to collaborate rather than compete with the other group.

The second mechanism explains the persistence of the differences between the groups in the second round. A negativity bias explains why the danger frame persists and exceeds the relevance of the information communicated between the two rounds of the game. There is a selectivity effect induced by the persistence of the defensive frame developed in the first round. This selectivity effect is probably enhanced by the fact that the groups had to decide under time pressure (Stuhlmacher and Champagne 2000). We can therefore conclude that the theory of selectivity of information processing due to an activated cognitive representation is also valid for groups. The feedback received by the groups regarding their total gain did not significantly help them to reconsider their initial representation and to process the game information more deeply.

\section{Conclusions}

Previous scholars acknowledged that an accurate understanding of the negotiation process and outcomes in dyads is only possible with a clear understanding of negotiators' mental models (Bazerman et al. 2000; Olekalns and Smith 2005). The results of our study suggest that in order to fully understand the inter-group negotiation process and outcomes one needs to first understand the development and dynamics of collective cognitive representations. With identical knowledge about the negotiation game, groups represent the negotiation situation differently, depending on the way in which the game information is framed. Of particular interest here is the role played by the information framed as danger in the development and dynamics of the collective cognitive representation. The negotiation's outcomes depended not on the information they had, which was similar for the two groups involved in a negotiation pair, but on the way this information is represented. In this respect it is particularly 
important to understand, for example, the role of communication in the development and dynamics of such collective representations.

Another relevant result of the present study concerns the selectivity of information processing in groups, due to an activated cognitive representation. An activated cognitive representation will guide information processing by selecting information that is congruent with the activated representation and by ignoring information that is incongruent with the activated representation. Further investigation is needed in more controlled settings to fully understand the selectivity in information processing in groups.

\section{Appendix 1}

The negotiation game adapted from the "disarmament exercise" developed by Lewicki et al. (1999).

\section{The Framing Condition (Danger)}

The purpose of this exercise is to engage you in working together in a small group. You have to make decisions about the confrontation with another group. Each group represents a country. You represent a small country, which was for many years under the dominance of other countries. Other countries wanted all the time to benefit from your rich natural resources. Your country has just earned its independence and you have to confront a group, representing a big and powerful country. The exercise consists in the confrontation of the two teams. Each group can make decisions in the name of its country. Groups can make decisions referring to the activation of the weapons each country has.

\section{The No-framing Condition (Neutral)}

The purpose of this exercise is to engage you in working together in a small group. You have to make decisions about the nature of your relationship with another group. Each group represents a country. The exercise consists in interacting with the other group. Each group can make decisions in the name of its country. Groups can make decisions referring to the activation of the weapons each country has.

\section{Common Information (for Both Groups)}

Each group will have the opportunity to make decisions about a series of "moves". The outcome of those moves (in terms of the number of points that your team earns or loses) will be determined by the choice that your group makes, and the choice that the other group makes. Your group cannot independently determine its outcomes in this situation. In conclusion, the number of points earned in this exercise by your group is determined by:

- Your group's behavior towards the other group

- The other group's behavior towards your own group

- The negotiations between groups when this is permitted. 
The Rules of the Game

\section{The Objective of the Exercise}

Your team is going to engage in a disarmament exercise in which you can earn or lose points. Each group has the power to decide the strategy for the activation and use of the weapons of its country. The aim of your team is to earn as many points as you can. The other team has the same objectives.

\section{The Task}

Each team is given 20 cards. These represent your weapons; each card represents a weapon. Each card has one side marked with an $\mathrm{X}$ and an unmarked side. When the marked side of the card is displayed, this indicates that the weapon is armed. Conversely, when the blank side of the card is displayed, this shows the weapon to be unarmed. Each team also has an A (attack) card. The way in which this card can be used will be explained later.

At the beginning of the exercise, each team places 10 of its 20 weapons (cards) in the armed position with the marked side up, and the remaining 10 in the unarmed position with the marked side down. All weapons will remain in your possession throughout the exercise; they must be placed so that the referee can see them, but the other team not.

The exercise consists of two rounds. Each round has up to seven moves. Payoffs are calculated after each round (not after each move), and are cumulative.

One move consists of a team turning two, one, or none of its weapons from the armed (X) to the unarmed (blank) status, or vice versa.

Each team has 3 min to decide on its own move and to make that move. There are 30-s periods between the moves. At the end of $3 \mathrm{~min}$, a team has turned two, one, or none of its weapons from the armed to the unarmed status, or from the unarmed to the armed status. Failing to decide on a move in the given time means no change can be made in the weapons' status until the next move. In other words, failure to make a move by the deadline counts as a move of zero weapons.

The length of the 3-min period is fixed and unalterable.

The referee of the exercise will verify each move for both teams after it has been made.

Each new round of the exercise begins with all weapons returned to their original position, 10 armed and 10 unarmed.

\section{The Payoffs}

Each team has initially an equal number of points (10 points). The referee who represents in this exercise The World Bank has the right to give credits to the teams.

Each team may announce an attack on the other team (by notifying the referee) during the 30 s following any 3-min period used to decide upon a move. To attack, they must display their A (attack) card to the referee. The moves of both teams during the decision period immediately before an attack count. An attack cannot be made during the negotiations.

If there is an attack (by one or both teams) the round ends.

The team with the greater number of armed weapons earns 0.5 points per member for each armed weapon it has over the number of armed weapons of the other team. These funds are paid directly from the other's team points. If both teams have the same number of armed weapons, the team that attacked pays 0.2 points per member for each armed weapon to The World Bank. The team that was attacked pays 0.1 points per member for each armed weapon 
to The World Bank. If both teams attacked, both pay 0.2 points per member for each armed weapon to The World Bank.

At the end of each round (seven moves), if there has been no attack, each team receives from The World Bank 0.2 points for each of its weapons that is at that point unarmed, and each team pays The World Bank 0.2 points for each weapon remaining armed. The team receives points from The World Bank if it has a higher number of unarmed than armed weapons and gives points to The World Bank if it has a higher number of armed than unarmed weapons.

Teams may run into a deficit with The World Bank. If there is a deficit at the end of both rounds, the deficit will be decided upon by the referee.

\section{The Negotiations}

Between moves, each team has the opportunity to communicate with the other team during the negotiations. You may not communicate with the other team before the first move.

Either team may call for negotiations (by notifying the referee) during any of the 30-s periods between decisions. A team is free to accept or reject any invitation from the other team.

The teams are required to negotiate after the third and sixth move.

Negotiations can last no longer than $5 \mathrm{~min}$. After each negotiation, the teams will have a 3-min period to decide upon their next moves.

The negotiations are bound only by the 5 -min period (time limit) and by the required appearance after the third and sixth moves. The teams are otherwise free to say whatever they choose, and to make any agreement they think is necessary to benefit from. They are not required to tell the truth. Similarly, teams are not bound by any agreements made during the negotiations, even when those agreements were made on good faith.

\section{Summary}

Each move can consist of turning over two, one, or zero of the weapons to the unarmed position-or the armed position.

The teams have $3 \mathrm{~min}$ to decide which of the above moves they will choose.

If there is no attack, at the end of the round (seven moves) each team receives 0.2 points for each unarmed weapon and loses 0.2 points for each armed weapon.

If there is an attack, the team with the greater number of armed weapons earns 0.5 points per member for each armed weapon it has over the number the other team has.

\section{References}

Baumeister RF, Bratslavsky E, Finkenauer C, Vohs KD (2001) Bad is stronger than good. Rev Gen Psychol 5(4):323-370

Bazerman MH, Curham JR, Moore DA, Valley KL (2000) Negotiation. Annu Rev Psychol 51:279-314

Curşeu PL (2003) Formal group decision-making. A social cognitive approach. ASCR Press, Cluj-Napoca, RO

Curşeu PL (2006) Emergent states in virtual teams. A complex adaptive systems perspective. J Inform Technol 21(4):249-261

Dunegan KJ (1993) Framing, cognitive modes and image theory: toward an understanding of a glass half full. J Appl Psychol 78:491-503

Druckman D (1994) Determinants of compromising behavior in negotiation. A Meta-analysis. J Conflict Resolut 38(3):507-556 
Eden C, Ackerman F (2001) Group decision and negotiation in strategy making. Group Decis Negotiat 10:119_ 140

Elliot M, Gray B, Lewicki R (2002) Lessons learned about the framing of intractable environmental conflicts. In: Lewicki R, Gray B, Elliot M (eds) Making sense of intractable environmental conflicts: Concepts and cases. Island Press, Washington, DC, pp 409-436

Fiske ST, Taylor SE (1991) Social cognition, 2nd edn. McGraw-Hill, NewYork

Gray B (2004) Strong opposition: Frame-based resistance to collaboration. J Community Appl Soc Psychol 14:166-176

Gingerenzer G, Hoffrage U, Kleinbölting H (1991) Probabilistic mental models: A Brunswickian theory of confidence. Psychol Rev 98:506-528

Hanke R, Gray B, Putnam L (2002) Differential framing of environmental disputes by stakeholder groups. Academy of Management Conflict Management Division 2002 Meetings, No. 13171. http://ssrn.com/abstract=320364. Accessed 1 Apr 2004

Hinsz VB, Tindale RS, Vollrath DA (1997) The Emerging conceptualization of groups as information processors. Psychol Bull 121(1):43-64

Ito TA, Larsen JT, Smith KN, Cacioppo JT (1998) Negative information weighs more heavily on the brain: The negativity bias in evaluative categorizations. J Pers Soc Psychol 75(4):887-900

Ito TA, Cacioppo JT (2005) Various on a human universal: Individual differences in positivity offset and negativity bias. Cogn Emot 19(1):1-26

Jarymowicz M, Bar-Tal D (2006) The dominance of fear over hope in the life of individuals and collectivities. Eur J Soc Psychol 36:367-392

Jou J, Shanteau J, Harris RJ (1996) An information processing view of framing effects: the role of causal schemas in decision-making. Mem Cogn 24:1-15

Kühberger A (1998) The influence of framing on risky decisions: a meta-analysis. Organ Behav Hum Decis Process 75(1):23-55

Lamm H (1988) A review of our research on group polarization: Eleven experiments on the effect of group discussion on risk acceptance, probability estimation and negotiation positions. Psychol Rep 62:807-813

Larrick RP, Blount S (1997) The claiming effect: Why players are more generous in social dilemmas than in ultimatum games. J Pers Soc Psychol 72:810-825

Levin IP, Schneider SL, Gaeth GJ (1998) All frames are not created equal: a typology and critical analysis of framing effects. Organ Behav Hum Decis Proces 76(2):149-188

Lewicki RJ, Saunders DM, Minton JW (1999) Negotiation: readings, exercises and cases. McGraw-Hill, Boston

Lupfer MB, Weeks M, Dupuis S (2000) How pervasive is the negativity bias in judgments based on character appraisal? Pers Soc Psychol Bull 26(11):1353-1366

Miclea M, Curşeu PL (2003) Framingul si mecanismele de apărare (Defence mechanisms and the framing effect) (in Romanian language). Cognitie, Creier, Comportament VII(4):383-392

Olekalns M (1994) Context, issues and frame as determinants of negotiated outcomes. Br J Soc Psy 33:197210

Olekalns M (1997) Situational cues as moderators of the frame-outcome relationship in negotiation. Br J Soc Psychol 36:191-209

Olekalns M (2002) Negotiation as a social interaction. Austr J Manage 27:39-46

Olekalns M, Smith PL (2005) Cognitive representations of negotiation. Austr J Manage 30:57-76

Paese PW, Bieser M, Tubbs ME (1993) Framing effects and choice shifts in group decision making. Organ Behav Hum Decis Process 56:149-165

Pinkley RL (1990) Dimensions of conflict frame: disputants interpretations of conflict. J Appl Psychol 75:117126

Rohrbaugh CC, Shanteau J (1999) Context, process and experience: research on applied judgment and decision-making. In: Durso F (ed) Handbook of applied cognition. Wiley, New York, pp 115-139

Sinaceur M, Neale M (2005) Not all threats are created equal: how implicitness and timing affect the effectiveness of threats in negotiations. Group Decis Negotiat 14:63-85

Stasser G, Titus W (1985) Pooling of unshared information in group decision making: Biased information sampling during discussion. J Pers Soc Psychol 48:1467-1478

Stasser G, Titus W (1987) Effects of information load and percentage of shared information on the dissemination of information during the group discussions. J Pers Soc Psychol 53:81-93

Stuhlmacher AF, Champagne MV (2000) The impact of time pressure and information on negotiation process and decisions. Group Decis Negotiat 9:471-491

Tversky A, Kahneman D (1981) The framing of decisions and the psychology of choice. Science 211:453-458

Weingart LR, Olekalns M, Smith PL (2004) Quantitative coding of negotiation behavior. Int Negotiation 9:441-455 
Wolfe RJ, McGinn KL (2005) Perceived power and its influence on negotiations. Group Decis Negotiat 14:320

Yzerbyt VY, Leyens JP (1991) Requesting information to form an impression: the influence of valence and confirmatory status. J Exp Psychol 27:337-356 